\title{
OBTENÇÃO E CARACTERIZAÇÃO DE FARINHAS DE CANIHUA (Chenopodium pallidicaule)
}

\author{
L. M. SALAS-VALERO ${ }^{1}$, D. R. TAPIA- BLÁCIDO² e F. C. MENEGALLI ${ }^{1}$ \\ ${ }^{1}$ Universidade Estadual de Campinas, Departamento de Engenharia de Alimentos \\ ${ }^{2}$ Universidade de São Paulo, Departamento de Química \\ E-mail para contato: ladysalasv@gmail.com
}

\begin{abstract}
RESUMO - A ênfase deste trabalho foi definir a metodologia ótima de extração de farinhas de grãos canihua (Chenopodium Pallidicaule) de duas variedades (cupi e illpa), para isso foram utilizadas duas metodologias de extração por moagem úmida em meio alcalino ou neutro. Foi analisado o efeito das duas metodologias de preparação nas suas propriedades físico-químicas e térmicas. Assim as farinhas extraídas por moagem em meio neutro de grãos de canihua apresentaram maiores teores de proteínas, cinzas, capacidade-antioxidante, temperatura e entalpias de gelatinizacão e maiores subunidades de proteínas. Enquanto, as farinhas de canihua extraídas por moagem úmida alcalina, obtiveram maiores teores de amilose, amido e lipídios. Os difratogramas das farinhas analisadas revelaram um padrão de cristalinidade tipo "A" com a presença de 4 picos. Um pico adicional em $2 \theta=20^{\circ}$ foi atribuído à associação da amilose dos grânulos de amido com lipídios resultando na cristalização do tipo V.
\end{abstract}

\section{INTRODUÇÃO}

A canihua (Chenopodium pallidicaule) é uma planta considerada um pseudocereal, cultivada na região dos Andes do sul do Peru e da Bolívia. Seu cultivo é encontrado em climas de 3600$4400 \mathrm{~m}$ de altitude e é resistente a baixas temperaturas $\left(-3^{\circ} \mathrm{C}\right)$. $\mathrm{O}$ grão de canihua é parente da quinoa (Chenopodium quinoa), apresentando um alto teor de amido, proteínas de alta qualidade (15-19,3\%), carboidratos (63-66\%), fibras dietéticas (18-25\%), ferro, cálcio, açucares e antioxidantes. (Repo-Carrasco et al., 2003, Repo-Carrasco-Valencia et al., 2010). A qualidade das proteínas pode ser atribuída à presença de aminoácidos essenciais balanceados, principalmente, um alto teor em lisina, isoleucina e triptofano, em maior quantidade que em outros cereais e equivalentes às proteínas do leite. Tradicionalmente os grãos de canihua são ligeiramente torrados e moídos, resultando em uma farinha nomeada cañihuaco. Esta pode ser consumida sozinha ou misturada com bebidas quentes ou frias, ou em forma de mingaus. Por outro lado, os grãos inteiros e a farinha torrada podem ser utilizados para fazer bebidas, sopas, pães, bolos e biscoitos (Mujica, 2009).

Apesar do valor nutricional da canihua, seu consumo está diminuindo devido à pouca difusão do seu cultivo e aos escassos estudos realizados para avaliar o potencial do grão tanto do ponto nutricional como da obtenção de novos produtos. Por isso o governo Peruano (lei $\mathrm{n}^{\circ} 29196$ ) e a Organização das Nações Unidas para Agricultura e Alimentação (FAO) estão incentivando o consumo da canihua, para promover a produção orgânica, contribuir com o alívio da pobreza e a conservação dos ecossistemas do Peru (Gonzales e Estrada, 2008, FAO, 2011). 
O objetivo do trabalho foi obter e caracterizar farinhas de grãos de canihua (variedades cupi e illpa) por duas metodologias de moagem úmida usando meio alcalino (solução de $\mathrm{NaOH}$ ) e meio neutro (água destilada), a fim avaliar seu potencial como ingrediente de alimentos.

\section{MATERIAIS E METODOS}

\subsection{Matéria prima}

As farinhas de canihua foram produzidas a partir de grãos de canihua das variedades cupi e illpa, obtidos de INIA (Instituto Nacional de Innovacion Agraria de Puno-Peru).

\subsection{Metodologias de obtenção de farinhas de canihua}

Moagem úmida em meio alcalino: Os grãos de canihua foram imersos em uma solução de $\mathrm{NaOH}$ a $0,25 \%(400 \mathrm{~mL})$ e essa mistura foi mantida a temperatura de refrigeração $\left(5^{\circ} \mathrm{C}\right)$ durante 24 horas. Logo a seguir, foi adicionado ao material original um volume de solução de hidróxido de sódio a $0,25 \%$, suficiente para permitir a moagem processadora (Wallita, São Paulo) durante dois minutos, a máxima potência. O material moído foi filtrado através de uma peneira de aço inoxidável de abertura 80 mesh. O resíduo não filtrado foi processado quatro vezes com adição de solução de $\mathrm{NaOH} 0,25 \%$, em quantidades suficientes para assegurar a moagem sem que se manifestasse elevação de temperatura no material. $\mathrm{O}$ material foi peneirado sucessivamente utilizando-se peneiras com aberturas de 200 e 270 mesh. Após, o pH do líquido filtrado foi ajustado utilizando-se solução de ácido clorídrico $0,2 \mathrm{~N}$ ate $\mathrm{pH} 4,5$. Após o ajuste do pH, o líquido foi centrifugado a $4500 \mathrm{rpm}$ durante 20 minutos. O sobrenadante foi descartado e os sólidos precipitados foram suspensos com água destilada e a suspensão foi neutralizada utilizando solução de $\mathrm{NaOH}$ 0,1N. Posteriormente, o material foi colocado em pratos de alumínio em camadas de 5 $\mathrm{cm}$ de espessura e foi secado em estufa de convecção forcada a $37^{\circ} \mathrm{C}$ por 24 horas.

Moagem úmida com maceração em meio neutro: Os grãos de canihua foram imersos em água destilada e esta mistura foi mantida a temperatura de refrigeração $\left(5^{\circ} \mathrm{C}\right)$ durante 24 horas. Logo a seguir, foi adicionado ao material original um volume de água destilada suficiente para permitir a moagem durante dois minutos, a máxima potência. O material moído foi filtrado através de uma peneira de aço inoxidável de abertura 80 mesh. O resíduo não filtrado foi processado cinco vezes com adição de água destilada, em quantidades suficientes para assegurar a moagem sem que se manifestasse elevação de temperatura no material. $O$ material foi peneirado sucessivamente utilizando-se peneiras com aberturas de 200 e 270 mesh. Após, a fração líquida filtrada foi colocada em pratos de alumínio em camadas de $5 \mathrm{~cm}$ de espessura e foi seca em estufa de convecção forcada a $37^{\circ} \mathrm{C}$ por 12 hora.

\subsection{Caracterização das farinhas de canihua}

Composição Centesimal: O conteúdo de umidade, cinzas e proteína foram determinados pelos métodos da AOAC (2005). O teor de lipídios foi determinado pelo método de Bligh e Dyer (1959). O teor de amilose foi determinado segundo o método colorimétrico do iodo simplificado de acordo com a metodologia usada por Martínez e Cuevas (1989).

Perfil de ácidos graxos dos lipídios extraídos das farinhas de canihua: O óleo das farinhas de canihua foi extraído pelo método de Bligh e Dyer (1959). A composição de ácidos graxos foi 
determinada utilizando a metodologia de Hartmann e Lago (1973).

Perfil eletroforético das proteínas das farinhas de canihua: Esta analise foi realizada segundo a metodologia descrita por Laemmli, (1970).

Conteúdo de fenóis totais e capacidade antioxidante: O conteúdo total de fenóis foi quantificado utilizando o método colorimétrico de Folin-Ciocalteau, e a capacidade antioxidante pelo Método de Redução do Ferro (FRAP)

Difração de raios-X: Foram obtidos difratogramas da farinha de canihua. Os ensaios foram realizados a temperatura ambiente no intervalo de ângulo $2 \theta$ variando de 2 a $50^{\circ}$. $\mathrm{O}$ aparelho utilizado foi um difratômetro universal de raios-X, Carl-Zeiss-Jena, modelo URD6 a uma velocidade de $1,2^{\circ} / \mathrm{min}$ operando a uma potência de $40 \mathrm{kV} / 20 \mathrm{~mA}$. O índice de cristalinidade (\%) das matérias primas foi quantitativamente estimado pelo método realizado por Nara e Komiya (1983) e usando o software Origin 8.0 (OriginLab Corporation, Massachusetts, EUA ).

Análises térmicas por calorimetria diferencial de varredura de suspensões de farinha de canihua: As propriedades térmicas das farinhas (temperatura de início $\left(\mathrm{T}_{\mathrm{o}}\right)$, temperatura de pico $\left(T_{p}\right)$ e temperatura final $\left(T_{f}\right)$ e entalpia de gelatinização) foram determinadas utilizando a metodologia utilizada por Tapia- Blácido et al., 2010. .

Análise estatística dos dados: Análise de variância (ANOVA) e o teste de Tukey foram realizados para determinar diferenças significativas a um nível de probabilidade de $5 \%(\mathrm{p}<0,05)$ entre as médias das propriedades das farinhas de canihua utilizando o Software Statistica V 7.0.

\section{RESULTADOS E DISCUSOES}

\subsection{Composição centesimal}

As farinhas obtidas por moagem úmida em meio alcalino e neutro a partir dos grãos de canihua das variedades cupi e illpa apresentaram diferenças significativas no teor de umidade, lipídios, cinzas proteínas, amido e amilose como apresentado na Tabela 1. Assim o teor de umidade mais baixo, porem maior teor de lipídio foi obtido para farinha da variedade illpa extraída em meio alcalino. Isto indica que a moagem em meio alcalino permitiu extrair mais lipídios do grão de canihua.

Tabela 1- Composição centesimal de grãos e farinha de canihua (Chenopodium pallidicaule)

\begin{tabular}{|c|c|c|c|c|c|c|c|}
\hline M.P. & A. & $\begin{array}{l}\text { Umidade } \\
\text { (g/100 m. s.) }\end{array}$ & $\begin{array}{c}\text { Cinzas } \\
\text { (g/100 m.s.) }\end{array}$ & $\begin{array}{l}\text { Lipídios } \\
\text { (g/100 m. s.) }\end{array}$ & $\begin{array}{l}\text { Proteínas } \\
\text { (g/100 m. s.) }\end{array}$ & $\begin{array}{l}\text { Amido* } \\
\text { (g/100 m. s.) }\end{array}$ & $\begin{array}{l}\text { Amilose } \\
\text { (g/100 m. s.) }\end{array}$ \\
\hline Grãos & $\begin{array}{l}\text { GC } \\
\text { GI }\end{array}$ & $\begin{array}{l}11,9 \pm 0,0^{\mathrm{c}} \\
12,4 \pm 0,5^{\mathrm{d}}\end{array}$ & $\begin{array}{l}4,9 \pm 0,18^{\mathrm{e}} \\
5,3 \pm 0,09^{\mathrm{d}}\end{array}$ & $\begin{array}{l}11,8 \pm 0,1^{\mathrm{c}} \\
11,9 \pm 0,3^{\mathrm{c}}\end{array}$ & $\begin{array}{l}15,6 \pm 0,1^{\mathrm{e}} \\
16,7 \pm 0,1^{\mathrm{f}}\end{array}$ & $\begin{array}{l}\text { ND } \\
\text { ND }\end{array}$ & $\begin{array}{l}9,8 \pm 0,0^{\mathrm{b}} \\
8,9 \pm 0,0^{\mathrm{a}}\end{array}$ \\
\hline Farinha & $\begin{array}{l}\text { CN } \\
\text { IN } \\
\text { CA } \\
\text { IA }\end{array}$ & $\begin{array}{c}10,7 \pm 0,0^{\mathrm{b}} \\
12,0 \pm 0,0^{\mathrm{c}, \mathrm{d}} \\
10,3 \pm 0,1^{\mathrm{b}} \\
9,2 \pm 0,1^{\mathrm{a}}\end{array}$ & $\begin{array}{c}4,6 \pm 0,1^{\mathrm{c}} \\
4,2 \pm 0,0^{\mathrm{b}} \\
1,5 \pm 0,1^{\mathrm{a}} \\
1,5 \pm 0,0^{\mathrm{a}}\end{array}$ & $\begin{array}{l}10,2 \pm 0,0^{\mathrm{a}} \\
10,3 \pm 0,0^{\mathrm{a}} \\
10,4 \pm 0,2^{\mathrm{a}} \\
11,4 \pm 0.1^{\mathrm{b}}\end{array}$ & $\begin{array}{l}13,4 \pm 0,1^{\mathrm{c}} \\
14,3 \pm 0,1^{\mathrm{d}} \\
12,3 \pm 0,2^{\mathrm{a}} \\
12,7 \pm 0,1^{\mathrm{b}}\end{array}$ & $\begin{array}{l}74,3 \pm 0,0^{\mathrm{a}} \\
74,2 \pm 0,5^{\mathrm{a}} \\
78,2 \pm 0,2^{\mathrm{c}} \\
76,7 \pm 0,1^{\mathrm{b}}\end{array}$ & $\begin{array}{l}12,2 \pm 0,1^{\mathrm{c}} \\
12,6 \pm 0,1^{\mathrm{d}} \\
13,3 \pm 0,0^{\mathrm{e}} \\
13,1 \pm 0,0^{\mathrm{e}}\end{array}$ \\
\hline
\end{tabular}

Letras iguais indicam que os valores não diferem estatisticamente em uma mesma coluna $(p \leq 0,05)$, GC e GI = grãos de canihua das variedades cupi e illpa; $\mathrm{CN}$ e $\mathrm{IN}=$ Farinhas de canihua das variedades cupi e illpa extraídas por moagem úmida em meio neutro; CA e IA = Farinhas de canihua das variedades cupi e illpa extraídas por moagem alcalina. Amido*= Calculado por diferença. ND: Não determinado, A.= Amostra, M.P.= Matéria prima. 
Por outro lado, o processo de extração de farinha de canihua afetou significativamente o teor de cinzas das farinhas de canihua. Maiores perdas de teor de cinzas foram observadas para as farinhas isoladas por o processo alcalino. Por conseguinte, as farinhas extraídas por moagem em meio neutro apresentaram valores significativamente maiores, quando comparados com as farinhas isoladas por moagem úmida.

Em relação ao teor de proteínas das farinhas produzidas neste trabalho, observa-se que o teor de proteínas das farinhas das variedades cupi e illpa, que foram extraídas em moagem com água destilada, ou seja, em meio neutro foram maiores daquelas extraídas em moagem alcalina. Isto foi diferente ao observado para os grãos de amaranto (Tapia-Blácido, 2003) onde o uso de uma solução de $0,25 \%$ para a moagem permitiu a extração tanto do amido como a solubilização das proteínas (albumina-1, globulina, albumina-2, gluteina). Por outro lado, na extração de proteínas do grão de quinoa foi observado que o uso de meios alcalinos $(\mathrm{pH}>10)$ produz alterações estruturais significativas e mudanças nas propriedades funcionais das proteínas, mudando sua carga proteica, grau de desnaturação, obtendo proteínas desdobradas, expondo os grupos funcionais S-H, e estabelecendo novas ligações covalentes tais como S-S (Valenzuela et al., 2013)

Neste trabalho, a extração da farinha com agua destilada permitiu a extração de $86 \%$ das proteínas de grãos cupi e uma perda de $14 \%$ de proteínas, entretanto em meio alcalino $79 \%$ das proteínas foram extraídas originando uma perda de 21\%. Segundo Tapia-Blacido, (2003), o restante da proteína não encontrada na farinha isolada, encontra-se nas fibras descartadas durante o processo de extração.

\subsection{Analise de conteúdo de fenóis totais e capacidade antioxidante}

Na Tabela 2 observa-se que os métodos utilizados para a extração de farinha tiveram uma influencia significativa no conteúdo de fenóis totais, sendo maiores os valores obtidos nas farinhas extraídas em meio neutro, para ambas as variedades de canihua. Portanto em meio alcalino houve perda de fenóis totais. Os tratamentos alcalinos são eficazes na liberação de compostos fenólicos insolúveis associados às paredes celulares de polissacarídeos através ligações de hidrogênio e interações hidrofóbicas nos grãos e frutas, sendo estes compostos fenólicos difíceis de extrair com outros métodos convencionais (Madhujith e Shahidi, 2009). Neste caso, o decréscimo dos valores de fenóis totais nas farinhas de canihua poderia ser atribuído ao descarte do sobrenadante (solução de $\mathrm{NaOH}$ e compostos fenólicos e outros antioxidantes) durante o processo alcalino de obtenção de farinha depois do processo de centrifugado (Item 2.2).

Tabela 2 - Fenóis totais e capacidade antioxidante de extratos de farinhas de canihua

\begin{tabular}{|l|c|c|r|}
\hline Extratos & Amostras & $\begin{array}{c}\text { Fenóis totais } \\
(\mu \mathrm{mol} \mathrm{GAE} / \mathrm{g} \text { m.s. })\end{array}$ & $\begin{array}{r}\text { Capacidade antioxida } \\
(\mu \mathrm{mol} \mathrm{Trolox} / \mathrm{g}\end{array}$ \\
\hline \multirow{3}{*}{ Farinhas } & CN & $13,4 \pm 0,3^{\mathrm{d}}$ & $16,7 \pm 0,4^{\mathrm{c}}$ \\
& IN & $12,9 \pm 0,5^{\mathrm{d}}$ & $16,9 \pm 0,4^{\mathrm{c}}$ \\
& CA & $4,5 \pm 0,3^{\mathrm{b}}$ & $7,0 \pm 0,9^{\mathrm{b}}$ \\
& IA & $2,5 \pm 0,2^{\mathrm{a}}$ & $2,7 \pm 0,2^{\mathrm{a}}$ \\
\hline
\end{tabular}

Letras iguais indicam que os valores não diferem estatisticamente em uma mesma coluna $(\mathrm{p} \leq 0,05), \mathrm{CN}$ e IN = Farinhas de canihua das variedades cupi e illpa extraídas por moagem úmida em meio neutro; CA e IA = Farinhas de canihua das variedades cupi e illpa extraídas por moagem alcalina.

Os métodos de extração de farinhas também influenciaram significativamente os valores de capacidade antioxidante (FRAP) das farinhas extraídas pelo processo alcalino das farinhas de canihua das variedades cupi $(7,0 \mu \mathrm{mol}$ Trolox/g m.s.) e illpa $(2,7 \mu \mathrm{mol}$ Trolox/g m.s.), quando 
comparadas aos valores de capacidade antioxidante das farinhas de canihua das variedades cupi (16,7 $\mu \mathrm{mol}$ Trolox/g m.s.) e illpa (16,9 $\mu \mathrm{mol}$ Trolox/g m.s.) extraídas por moagem em meio neutro.

\subsection{Perfil de ácidos graxos dos lipídios totais}

Os óleos extraídos das farinhas de canihua apresentaram maior porcentagem de acido linoleico (46,9 - 48,5\%), seguidos por o acido oleico (24,8 -26,31\%), acido palmítico (14,0$14,6 \%$ ), acido linolênico (4,7-5,7\%) e acido esteárico (1,37-1,54\%), de modo que $75 \%$ de ácidos graxos são insaturados e $25 \%$ de ácidos graxos são saturados (Tabela 3).

Tabela 3 Perfil de ácidos graxos dos lipídios totais extraídos de farinhas de canihua

\begin{tabular}{|c|c|c|c|c|}
\hline $\begin{array}{c}\text { Acido graxo } \\
(\%)\end{array}$ & $\begin{array}{c}\text { Lipídios da farinha } \\
\text { CN }\end{array}$ & $\begin{array}{c}\text { Lipídios da farinha } \\
\text { IN }\end{array}$ & $\begin{array}{c}\text { Lipídios da } \\
\text { farinha CA }\end{array}$ & $\begin{array}{c}\text { Lipídios da farinha } \\
\text { IA }\end{array}$ \\
\hline C14:0 & $0.160 \pm 0.002^{\mathrm{a}}$ & $0.172 \pm 0.014^{\mathrm{a}}$ & $0.169 \pm 0.019^{\mathrm{a}}$ & $0.164 \pm 0.002^{\mathrm{a}}$ \\
\hline $\mathrm{C} 15: 0$ & $0.063 \pm 0.008^{\mathrm{a}}$ & $0.064 \pm 0.032^{\mathrm{a}}$ & $0.060 \pm 0.004^{\mathrm{a}}$ & $0.066 \pm 0.009^{\mathrm{a}}$ \\
\hline $\mathrm{C} 16: 0$ & $14.19 \pm 0.01^{\mathrm{a}}$ & $14.49 \pm 0.05^{\mathrm{a}}$ & $14.62 \pm 0.53^{\mathrm{a}}$ & $14.00 \pm 0.08^{\mathrm{a}}$ \\
\hline $\mathrm{C} 16: 1$ & $0.183 \pm 0.011^{\mathrm{a}}$ & $0.162 \pm 0.000^{\mathrm{a}}$ & $0.313 \pm 0.002^{\mathrm{a}}$ & $0.292 \pm 0.120^{\mathrm{a}}$ \\
\hline $\mathrm{C} 17: 0$ & $0.081 \pm 0.001^{\mathrm{a}}$ & $0.081 \pm 0.011^{\mathrm{a}}$ & $0.078 \pm 0.005^{\mathrm{a}}$ & $0.079 \pm 0.017^{\mathrm{a}}$ \\
\hline $\mathrm{C} 17: 1$ & $0.076 \pm 0.022^{\mathrm{a}}$ & $0.071 \pm 0.032^{\mathrm{a}}$ & $0.078 \pm 0.022^{\mathrm{a}}$ & $0.074 \pm 0.013^{\mathrm{a}}$ \\
\hline $\mathrm{C} 18: 0$ & $1.374 \pm 0.007^{\mathrm{a}}$ & $1.490 \pm 0.154^{\mathrm{a}}$ & $1.539 \pm 0.167^{\mathrm{a}}$ & $1.403 \pm 0.001^{\mathrm{a}}$ \\
\hline $\mathrm{C} 18: 1$ & $25.62 \pm 0.03^{\mathrm{a}, \mathrm{b}}$ & $26.31 \pm 0.512^{\mathrm{b}}$ & $25.98 \pm 0.41^{\mathrm{a}, \mathrm{b}}$ & $24.80 \pm 0.050^{\mathrm{a}}$ \\
\hline $\mathrm{C} 18: 2$ & $48.50 \pm 0.01^{\mathrm{a}}$ & $47.76 \pm 0.57^{\mathrm{a}}$ & $46.92 \pm 0.99^{\mathrm{a}}$ & $48.49 \pm 0.05^{\mathrm{a}}$ \\
\hline $\mathrm{C} 18: 3$ & $5.14 \pm 0.01^{\mathrm{b}}$ & $4.66 \pm 0.08^{\mathrm{a}}$ & $5.34 \pm 0.11^{\mathrm{b}}$ & $5.69 \pm 0.04^{\mathrm{c}}$ \\
\hline $\mathrm{C} 20: 0$ & $0.678 \pm 0.006^{\mathrm{a}}$ & $0.71 \pm 0.023^{\mathrm{a}, \mathrm{b}}$ & $0.74 \pm 0.011^{\mathrm{a}} \mathrm{b}$ & $0.76 \pm 0.041^{\mathrm{b}}$ \\
\hline $\mathrm{C} 20: 1$ & $1.04 \pm 0.01^{\mathrm{b}}$ & $0.99 \pm 0.00^{\mathrm{a}}$ & $1.03 \pm 0.02^{\mathrm{a}, \mathrm{b}}$ & $1.03 \pm 0.00^{\mathrm{a}, \mathrm{b}}$ \\
\hline $\mathrm{C} 22: 0$ & $0.65 \pm 0.013^{\mathrm{a}}$ & $0.64 \pm 0.002^{\mathrm{a}}$ & $0.65 \pm 0.016^{\mathrm{a}}$ & $0.64 \pm 0.021^{\mathrm{a}}$ \\
\hline C22:1 & $0.78 \pm 0.007^{\mathrm{a}}$ & $0.76 \pm 0.019^{\mathrm{a}}$ & $0.78 \pm 0.028^{\mathrm{a}}$ & $0.78 \pm 0.007^{\mathrm{a}}$ \\
\hline $\mathrm{C} 24: 0$ & $0.24 \pm 0.144^{\mathrm{a}}$ & $\mathrm{ND}$ & $0.26 \pm 0.017^{\mathrm{a}}$ & $0.21 \pm 0.051^{\mathrm{a}}$ \\
\hline
\end{tabular}

Letras iguais indicam que os valores não diferem estatisticamente em uma mesma linha ( $\leq \leq 0,05), \mathrm{CN}$ e IN = Farinhas de canihua das variedades cupi e illpa extraídas por moagem úmida em meio neutro; CA e IA = Farinhas de canihua das variedades cupi e illpa extraídas por moagem alcalina. ND: Não determinado

Por outro lado, as farinhas extraídas por moagem úmida em meio neutro de grãos illpa obtiveram valores estatisticamente maiores de acido oleico C18:1 (26,31\%), porem menores valores de ácidos C18:3 e C20:1 quando comparados aos óleos farinhas das duas variedades extraídas por moagem úmida alcalina. No entanto, o óleo extraído de farinhas isoladas por moagem alcalina de grãos illpa apresentou um valor ligeiramente maior de acido linolênico C18:3 (5,69\%), porem menores valores de C18:1 em relação aos óleos extraídos de farinhas isoladas por moagem úmida em meio neutro.

\subsection{Perfil eletroforético}

No perfil eletroforético das proteínas dos grãos de canihua das variedades cupi e illpa (Figura 1) podem ser observadas bandas em baixos pesos moleculares $(<14 \mathrm{kDa})$, três bandas entre pesos molecular de 14,4-20,1 kDa, duas bandas evidentes entre 20,1 e $30 \mathrm{kDa}$, assim como três bandas entre pesos moleculares de 30 e $43 \mathrm{kDa}$, três bandas menos concentradas entre 43 e 67 $\mathrm{kDa}$ e uma banda em maior peso molecular (> $94 \mathrm{kDa})$ que não pode ser separada. Nas farinhas foram observadas as mesmas bandas que nos grãos, mas de menor intensidade, o que significa menor concentração dos diferentes tipos de proteínas nas farinhas quando comparadas com o grão. 
Este efeito foi menos intenso nas farinhas obtidas por moagem com água destilada. Estas bandas apresentadas pelos grãos e farinhas de canihua poderiam ser atribuídas a proteínas como albuminas, globulinas, prolaminas e glutelinas (Repo-Carrasco, 2003).

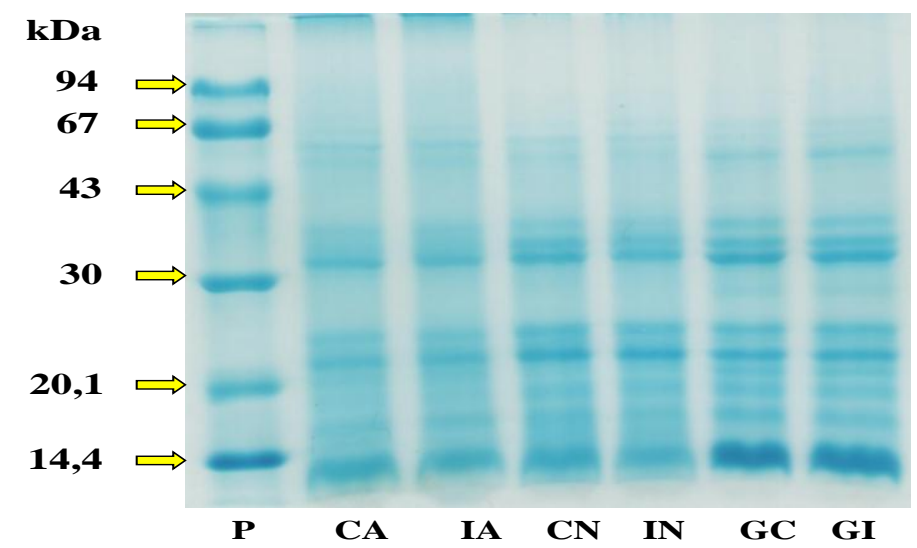

Figura 1 - Perfil eletroforético do grão e das farinhas de canihua. Coluna (P), mistura de frações puras de proteínas utilizadas como marcadores de massa molecular. Colunas (CA) e (IA), farinhas de canihua das variedades cupi e illpa extraídas por moagem úmida em meio alcalino. Colunas (CN) e (IN), farinhas de canihua das variedades cupi e illpa extraídas por moagem úmida em meio neutro. Colunas (GC) e Coluna (GI), grãos moídos de canihua das variedades cupi e illpa.

\subsection{Difratogramas Drx das farinhas}

As difrações de raios-X dos grãos e das farinhas analisados neste trabalho, mostraram difratogramas semelhantes, com 4 picos em $2 \theta=15,17,18,23^{\circ}$ e um pico adicional em $2 \theta=20^{\circ}$ atribuído a associação da amilose dos grânulos de amido com lipídios (ácidos graxos) presentes nos grãos e farinhas de canihua (Figuras 2).

a)

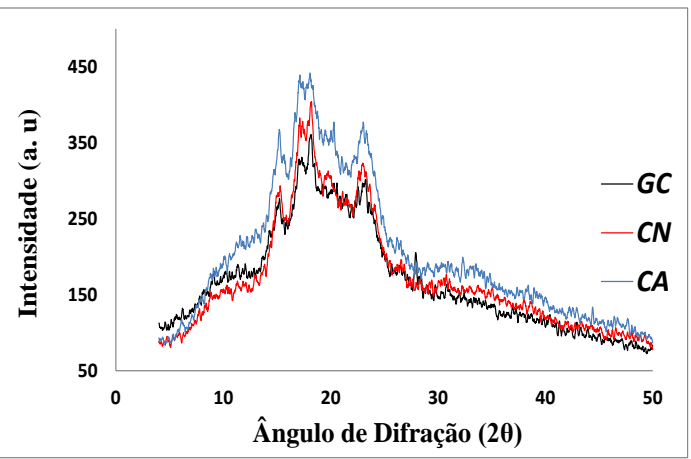

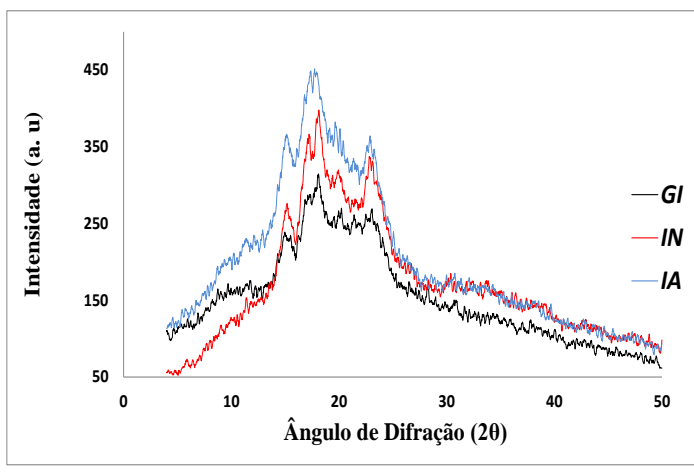

Figura 2 - Difratograms Drx de grãos e farinhas de canihua das variedades a) Cupi ; b) Illpa

As farinhas extraídas dos grãos de canihua (variedades cupi e illpa) por moagem úmida alcalina apresentaram maiores valores de cristalinidade de 28,93 e 31,04\% respectivamente, quando comparadas às farinhas isoladas por moagem úmida em meio neutro. Este comportamento foi atribuído a maior intensidade dos picos de difração como consequência do maior teor de amilose e maior formação de complexos amilose-lipídios (Figura 2). 


\subsection{Propriedades térmicas}

Verificou-se que os métodos utilizados para extrair as farinhas de canihua influenciaram suas propriedades térmicas, sendo que as farinhas (CN e IN) extraídas por moagem em meio neutro apresentaram valores significativamente maiores de temperatura e entalpias de gelatinização, quando comparadas com as farinhas (CA e IA) extraídas por moagem úmida alcalina (Tabela 4). Vários autores reportaram a influencia do método de extração alcalino conhecido como gelatinização ao frio, nas propriedades térmicas dos amidos (Palacios-Fonseca et al., 2013).

Tabela 4 - Resultados das temperaturas de gelatinização das farinhas de canihua

\begin{tabular}{|c|c|c|c|c|c|}
\hline & Amostras & $\begin{array}{c}\mathbf{T}_{\mathbf{0}} \\
\left.\mathbf{(}^{\circ} \mathbf{C}\right)\end{array}$ & $\begin{array}{c}\mathbf{T}_{\mathbf{p}} \\
\left.\mathbf{(}^{\circ} \mathbf{C}\right)\end{array}$ & $\begin{array}{c}\mathbf{T}_{\mathbf{f}} \\
\left({ }^{\circ} \mathbf{C}\right)\end{array}$ & $\begin{array}{c}\Delta \mathrm{H} \\
(\mathrm{J} / \mathrm{g} \mathrm{de} \mathrm{amido})\end{array}$ \\
\hline \multirow{3}{*}{ Farinhas } & CN & $62,3 \pm 0,3^{\mathrm{d}}$ & $67,8 \pm 0,2^{\mathrm{d}}$ & $76,0 \pm 0,2^{\mathrm{c}}$ & $6.0 \pm 0.2^{\mathrm{b}}$ \\
& IN & $59,8 \pm 0,3^{\mathrm{c}}$ & $67,1 \pm 0,2^{\mathrm{c}}$ & $77,2 \pm 0.1^{\mathrm{d}}$ & $7.5 \pm 0.2^{\mathrm{c}}$ \\
& CA & $57,9 \pm 0,0^{\mathrm{b}}$ & $64,2 \pm 0,1^{\mathrm{b}}$ & $73,3 \pm 0.2^{\mathrm{a}}$ & $4.8 \pm 0.2^{\mathrm{a}}$ \\
& IA & $56,6 \pm 0.0^{\mathrm{a}}$ & $63,7 \pm 0,2^{\mathrm{a}}$ & $75,5 \pm 0.1^{\mathrm{b}}$ & $5.9 \pm 0.2^{\mathrm{b}}$ \\
\hline
\end{tabular}

Letras iguais indicam que os valores não diferem estatisticamente em uma mesma coluna $(p \leq 0,05), \mathrm{CN}$ e IN = Farinhas de canihua das variedades cupi e illpa extraídas por moagem úmida em meio neutro; CA e IA = Farinhas de canihua das variedades cupi e illpa extraídas por moagem alcalina.

Por outro lado, as farinhas (CN, CA) extraídas de grãos de canihua da variedade cupi possuem valores ligeiramente maiores de temperaturas de gelatinização $\left(T_{o}\right.$ e $\left.T_{p}\right)$, porem menores valores de entalpia, em relação às propriedades térmicas de farinhas (IN, IA) extraídas de grãos da variedade illpa. Podendo-se concluir que a estrutura dos grânulos de amido da farinha extraída de grãos de canihua da variedade cupi é mais resistente.

\section{CONCLUSÕES}

A metodologia usada para extrair as farinhas modifica a suas propriedades. Sendo que quando se utilizou a extração por moagem em meio neutro se obteve menores perdas de proteínas, cinzas e maiores teores de fenóis totais, capacidade antioxidante, subunidades de proteína, o que resultou em temperaturas e entalpias de gelatinização maiores quando comparadas às das farinhas obtidas por moagem úmida alcalina. Por outro lado, a farinha extraída por moagem em meio alcalino de grãos de canihua da variedade illpa, apresentaram maiores valores de cristalinidade e maior teor de lipídios com valores ligeiramente maiores de linolênico quando comparado às outras farinhas extraídas. Por tanto, farinhas extraídas de grãos de canihua, apresentam-se como ingrediente potencial de alimentos por apresentar altos valores de proteínas (presença de albuminas, globulinas, prolaminas e glutelinas), cinzas, amido, ácidos graxos como linoleico, oleico, linolênico e palmítico e boa capacidade antioxidante.

\section{REFERÊNCIAS}

AOAC - Association of Official Analytical Chemists. Official Methods of analysis of AOAC International. 18. ed. Washington: AOAC, 2005.

BLIGH, E. G., DYER, W. J., A rapid method of total lipid extraction and purification. Can. J. Biochem. Physiol, v. 37, p. 911-917, 1959.

FAO, http://www.rlc.fao.org/es/agricultura/produ/cdrom/contenido/libro07/Cap3_3.htm\#2, 
acessada em Junho de 2011.

GONZALES L.; ESTRADA A. Ley de promoción de la producción orgánica o ecológica, ley $\mathrm{N}^{\circ}$ 29196, Congreso da república del Perú, 29 de enero de 2008.

HARTMANN L and LAGO R, Rapid preparation of fatty acid methyl esters from lipids. Lab Pract v. 22, p.475-476, 1973.

LAEMMLI UK, Cleavage of structural proteins during the assembly of the head of bacteriophage T4. Nature, v. 227, p. 680-685, 1970.

MADHUJITH T., SHAHIDI F. Antioxidant potential of barley as affected by alkaline hydrolysis and release of insoluble-bound phenolics, Food Chemistry, v. 117, p. 615-620, 2009.

MARTÍNEZ, C.; CUEVAS, F. Evaluación de la calidad culinaria y molinaria del arroz. Guía de studio. Cali: CIAT, p. 75, 1989.

MUJICA A. Potencialidades de los cultivos andinos en el desarrollo nacional y su riqueza nutricional y cultural. Revista Thaki, Instituto Peruano de Investigación Quechua Aymara, 2009.

NARA, S., KOMIYA, T., Studies on the relationship between water-satured state and crystallinity by the diffraction method for moistened potato starch. Starch/Starke, v. 35, p. 407-410, 1983.

PALACIOS-FONSECA, A.J.; CASTRO-ROSAS, J.; GÓMEZ-ALDAPA, C.A.; TOVARBENITEZ, T.; MILLAN-MALO, B.M.; DEL REAL, A. AND RODRÍGUEZ-GARCÍA, M.E. Effect of the alkaline and acid treatments on the physicochemical properties of corn starch, CyTA, Journal of Food, v. 11, p. 67 - 74, 2013. http://dx.doi.org/10.1080/19476337.2012.761651

REPO-CARRASCO, R.; ESPINOZA, C. AND JACOBSEN, S. Nutritional value and uses of andean crops quinoa (Chenopodium quinoa) and kañiwa (Chenopodium pallidicaule). Food Res. Int. v. 19, p. 179-189, 2003.

REPO-CARRASCO-VALENCIA R., HELlSTRÖM J. K., PIHLAVA J.-M., MATTILA P. H. Flavonoids and other phenolic compounds in Andean indigenous grains: Quinoa (Chenopodium quinoa), kañiwa (Chenopodium pallidicaule) and kiwicha (Amaranthus caudatus). Food Chemistry, v. 120, p.128-133, 2010.

TAPIA-BLÁCIDO, D. Filmes a base de derivados do amaranto. Dissertação (Mestrado em Engenharia de Alimentos) - Faculdade de Engenharia de Alimentos, Universidade Estadual de Campinas, 2003.

TAPIA-BLÁCIDO, D.; SOBRAL, P. J.; MENEGALLI, F. C. Potential of Amaranthus cruentus $B R S$ Alegria in the production of flour, starch and protein concentrate: chemical, thermal and rheological characterization. Journal of Food Engineering, J Sci Food Agric,; v. 90, p. 1185-1193, 2010 .

VALENZUELA, C.; ABUGOCH, L.; TAPIA, C. AND GAMBOA A. Effect of alkaline extraction on the structure of the protein of quinoa (Chenopodium quinoa Willd.) and its influence on film formation, Int. J. Food Sci. Technol, v. 48, p. 843-849, 2013. 